\title{
ESTUDO DE BENEFICIAMENTO QUÍMICO E FÍSICO E CARACTERIZAÇÃO DE BAUXITAS DO PARÁ
}

\author{
D. S. G. Almeida ${ }^{1,2}$, F. A. N. G. Silva ${ }^{1}$, C. G. M. Santos ${ }^{1,2}$, M. E. Medeiros ${ }^{1}$, J. A. Sampaio ${ }^{2}$, F. M. S. Garrido ${ }^{1}$ \\ ${ }^{1}$ Universidade Federal do Rio de Janeiro, Instituto de Química, Avenida Athos da Silveira Ramos, 149, bloco A, sala 630, \\ Cidade Universitária; Rio de Janeiro, RJ, 21941-909, Brasil. \\ ${ }^{2}$ Centro de Tecnologia Mineral / CETEM-MCT, Avenida Pedro Calmon, 900, Cidade Universitária; Rio de Janeiro, RJ, 21941- \\ 908, Brasil. \\ diego.seixas@ufrj.br
}

\section{Artigo submetido em setembro/2012 e aceito em novembro/2012}

\section{RESUMO}

As camadas de bauxita cristalizada (BC) e bauxita Por meio da difração de raios X (DRX) observa-se um cristalizada amorfa (BCA) que compõem o perfil geológico do nordeste do Pará foram submetidas às etapas de beneficiamento e adequadas aos ensaios de bancada, sendo submetidas ao estudo da influência do $\mathrm{pH}$ na distribuição granulométrica. A mudança no $\mathrm{pH}$ da aumento no teor de caulinita nas frações mais finas. $O$ estudo do efeito do $\mathrm{pH}$ na distribuição granulométrica mostrou que o ajuste das condições da polpa pode ser uma alternativa viável à diminuição da sílica reativa (caulinita) contida nas bauxitas marginais.

PALAVRAS-CHAVE: : Bauxita, Caulinita, Caracterização.

\section{PHYSICAL AND CHEMICAL ORE DRESSING STUDIES AND CHARACTERIZATION OF BAUXITES FROM PARÁ}

\begin{abstract}
The layers of crystallized bauxite (CB) and crystallized amorphous bauxite (ACB) that compound the bauxite's geological profile of the northeastern Pará were submitted to the stages of ore dressing in order to become appropriated to the bench tests, being subjected to the study of the influence of the $\mathrm{pH}$ in the particle size distribution. The modification in the $\mathrm{pH}$ of
\end{abstract}

the slurry, changes the particle size distribution of bauxite. By X-ray diffraction (XRD) can be observe an increase in kaolinite content in the fine fractions. The study of the effect of $\mathrm{pH}$ on particle size distribution showed that the setting conditions of the slurry may be a viable alternative to the reduction of reactive silica (kaolinite) contained in marginal bauxite.

KEY-WORDS: Bauxite, Kaolinite, Characterization. 


\section{ESTUDO DE BENEFICIAMENTO QUÍMICO E FÍSICO E CARACTERIZAÇÃO DE BAUXITAS DO PARÁ}

\section{INTRODUÇÃO}

A Bauxita é uma rocha de coloração avermelhada, composta de uma mistura impura de minerais de alumínio. Apesar de ser frequentemente descrita como o minério de alumínio, a bauxita não é uma espécie mineral propriamente dita, mas um material heterogêneo formado de uma mistura de oxihidróxidos de alumínio $\left(\mathrm{AlO}_{x}(\mathrm{OH})_{3-2 x}, 0<x<1\right)$ contendo impurezas. Assim, a rocha bauxita é composta por uma combinação dos minerais gibbsita $(\gamma-$ $\left.\mathrm{Al}(\mathrm{OH})_{3}\right)$, diásporo $(\gamma-\mathrm{AlO}(\mathrm{OH}))$ e boehmita $(\alpha-\mathrm{AlO}(\mathrm{OH}))$, sendo que, suas proporções na rocha variam muito de um depósito para outro, assim como, o tipo e a quantidade das impurezas do minério. A bauxita brasileira é do tipo gibbsítica. Dentre as impurezas que compõem esta rocha, destacam-se a caulinita, o quartzo, a hematita, a goethita, a alumino-goethita, a ilmenita, o rutilo e o anatásio. A proporção dos óxidos de ferro determina a coloração da rocha. Assim, a bauxita branca contém de 2 a $4 \%$ de óxidos de ferro e na bauxita vermelha essa proporção é de 25\% (SILVA, 2011).

A produção anual de bauxita no mundo é superior a 120 milhões de toneladas e o Brasil detém, aproximadamente, $6,58 \%$ das reservas mundiais de bauxita, ocupando a quarta posição na classificação mundial. Das reservas brasileiras, o Estado do Pará detém cerca de $90 \%$. A produção brasileira é da ordem de 14 milhões de toneladas e cerca de $95 \%$ deste montante é utilizado na obtenção do alumínio metálico por meio do processo Bayer seguido do processo Hall-Héroult (GONÇALVES, 2008). Os outros $5 \%$ são aplicados na fabricação de materiais refratários, abrasivos, velas de ignição, cerâmicas, entre outros.

A bauxita do Nordeste do Pará é constituída pelas seguintes camadas (Figura 1): nodular (BN), nodular cristalizada (BNC), cristalizada (BC), cristalizada amorfa (BCA) e amorfa (BA). Em princípio, somente a camada BC, que corresponde a $30 \%$ do perfil geológico, é explorada comercialmente. As camadas nodular e nodular cristalizada possuem elevado teor de ferro e as camadas cristalizada amorfa e amorfa possuem um elevado teor de sílica reativa, assim como, outras impurezas. Desse modo, esses tipos de bauxita são considerados marginais, cujo aproveitamento carece de tecnologias especiais decorrentes do seu elevado conteúdo de impurezas (SILVA et al., 2011).

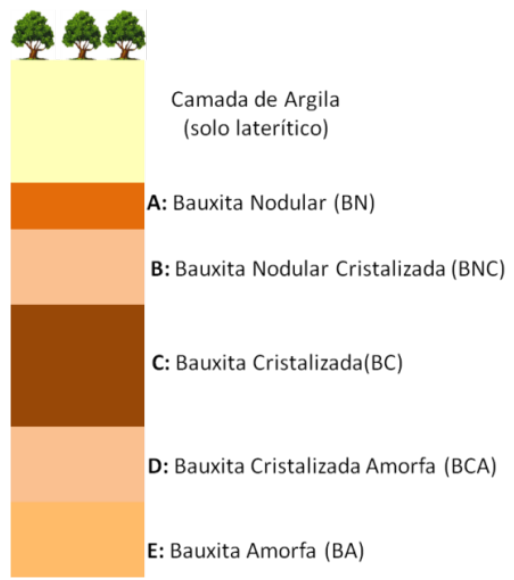

Figura 1. Perfil geológico de ocorrência da bauxita no NE do Pará. 
Para a bauxita ser considerada aproveitável ao processo Bayer a razão mássica entre $\mathrm{Al}_{2} \mathrm{O}_{3}$ disponivel $/ \mathrm{SiO}_{2}$ reativa deve ser maior ou igual a 10 , caso contrário a bauxita é considerada marginal, isto é, imprópria à produção de alumina pelo processo Bayer. A caulinita é a principal fonte de sílica reativa contida nas bauxitas do tipo gibbsítica e, nas condições do processo Bayer, reage e ocasiona um consumo elevado de $\mathrm{NaOH}$ e perda de alumina (SILVA et al., 2012).

Desta forma, a ausência de processos capazes de remover a caulinita, maior portadora de sílica reativa, limita, de forma significativa, o aproveitamento de muitos minérios de alumínio, como é o caso das bauxitas marginais do Nordeste do Pará. O aproveitamento desses minérios de alumínio significaria duplicar as reservas de bauxita do Brasil (SILVA, 2011).

Os objetivos deste trabalho consistiram em caracterizar e comparar as bauxitas comerciais e marginais com o intuito de estudar e desenvolver métodos de separação caulinita/gibbsita visando o aproveitamento de camadas marginais do perfil geológico da bauxita do Nordeste do Pará, inutilizadas atualmente.

\section{MATERIAIS E MÉTODOS}

\section{Amostragem}

As amostras utilizadas nos estudos foram provenientes de duas camadas do perfil geológico da bauxita do Nordeste do Pará, uma delas corresponde à bauxita cristalizada (BC), que já é comumente aproveitada pela indústria, e a outra corresponde à bauxita cristalizada amorfa (BCA), uma bauxita marginal inadequada ao processo Bayer devido aos elevados teores de sílica reativa.

As amostras, com granulometria inferior a $100 \mathrm{~mm}$, foram homogeneizadas em pilha prismática, da qual foram retiradas alíquotas para posterior análise granulométrica (AQUINO e OLIVEIRA, 2007). Estas amostras foram cominuídas, com o auxílio do britador de mandíbulas (BARBATO e SAMPAIO, 2007). O produto de britagem foi submetido a fracionamento em peneira de abertura de 1,65 $\mathrm{mm}$. A fração da britagem acima de 1,65 $\mathrm{mm}$ foi rebritada em um britador de rolos, operando em circuito fechado, com uma peneira de abertura de 1,65 $\mathrm{mm}$. A fração da britagem, inferior a 1,65 mm, passou pela etapa de deslamagem em peneira para a remoção da fração fina (abaixo de $37 \mu \mathrm{m}$ ). A fração acima de $37 \mu \mathrm{m}$ do processo de deslamagem foi homogeneizada com a fração de granulometria inferior a 1,65 mm do britador de rolos, sendo retiradas amostras de $20 \mathrm{~kg}$ (SILVA et al., 2009). Foi feita uma nova pilha de homogeneização com a amostra de $20 \mathrm{~kg}$, retirando-se alíquotas de $1 \mathrm{~kg}$ destinadas aos ensaios. $O$ procedimento descrito encontra-se ilustrado por meio da Figura 2.

\section{Estudo da Influência do pH na Distribuição Granulométrica}

Este estudo foi realizado segundo o método de ativação mecanoquímica (AZEVEDO et al., 2006). Assim, em um atritor, adicionou-se a polpa de bauxita e em seguida diferentes porcentagens mássicas em relação a polpa (1\% e 4\%) de um reagente alcalino, anteriormente descrito (SILVA et AL, 2012). A nova polpa foi encaminhada para a realização do peneiramento a úmido (SILVA E SAMPAIO, 2007). Para tanto, foi utilizado um peneirador vibratório, equipado com peneiras de abertura de 74 e $37 \mu \mathrm{m}$, segundo a série Tyler. A fração da bauxita com granulometria inferior a $37 \mu \mathrm{m}$ foi filtrada a vácuo obtendo-se uma torta. A fração acima de $37 \mu \mathrm{m}$ e a torta foram secas em estufa $\left(100^{\circ} \mathrm{C}\right)$ e pesadas (SILVA et al., 2010). 
Após a pesagem, as frações foram devidamente preparadas por um procedimento de amostragem e encaminhadas para a caracterização química e mineralógica, usando as técnicas de difração de raios $X$, espectroscopia no infravermelho e análise química por via úmida (SILVA et al., 2009).

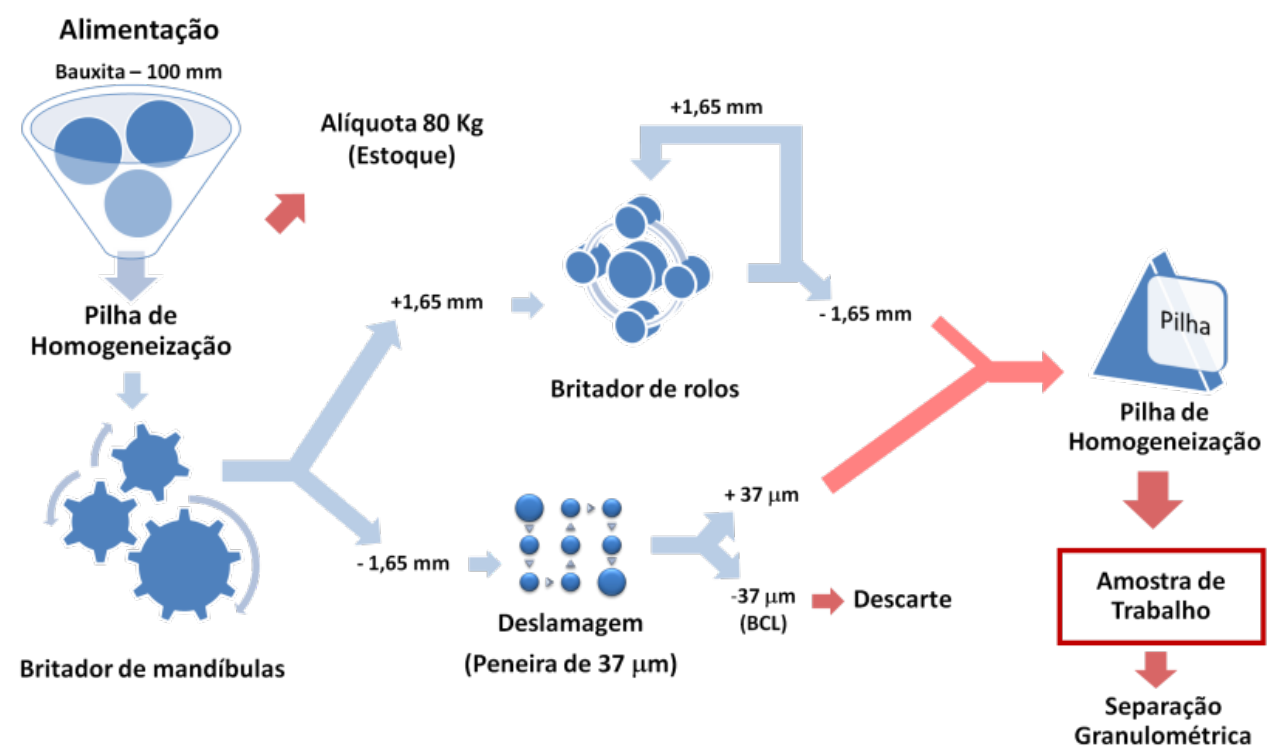

Figura 2. Esquema do preparo da amostra desde o recebimento do afloramento geológico até sua adequação aos ensaios.

\section{RESULTADOS E DISCUSSÃO}

Os resultados obtidos por meio de difratogramas das amostras da bauxita comercial (BC) e marginal (BCA), Figura 3, permitiram verificar que a BCA apresenta um teor de caulinita maior do que a $B C$, fato, este, evidenciado pelos picos relacionados ao mineral caulinita $(2 \theta=$ $\left.14,3^{0}\right)$ que são mais intensos na BCA, quando comparados aos da BC. Este observação já era esperada, pois a bauxita cristalizada amorfa encontra-se em uma camada mais profunda do perfil geológico, contendo maior quantidade de caulinita e, consequentemente, de sílica reativa. Embora o pico associado ao mineral gibbsita (alumina disponível) também seja intenso na bauxita marginal, a razão entre alumina disponível e sílica reativa é inferior a 10, aproximadamente 6 , conforme evidenciado pela análise química, Tabela 1 , indicando que esta parte do perfil é inadequado ao aproveitamento pelo processo Bayer. 


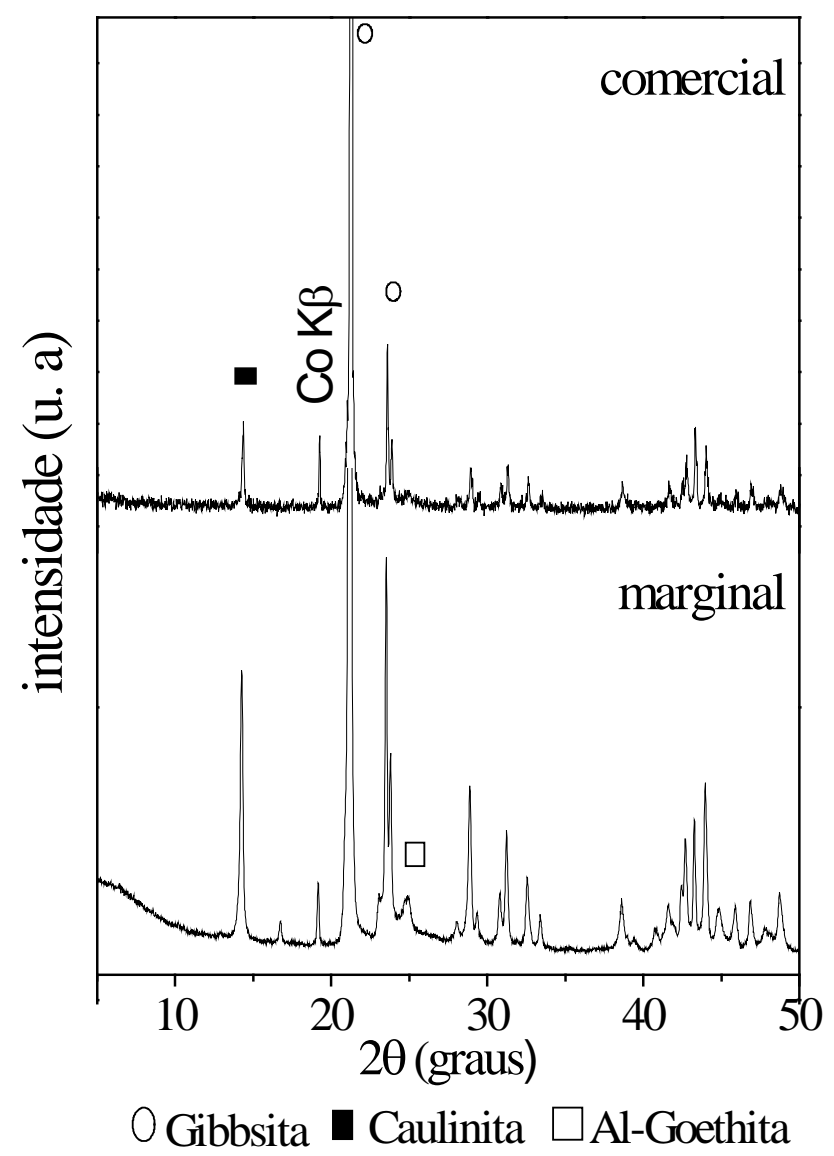

Figura 3. Difratograma das amostras de bauxita comercial (BC) e marginal (BCA).

Tabela 1. Resultados obtidos para as diferentes bauxitas por meio de análise química por via úmida.

\begin{tabular}{|c|c|c|}
\hline Amostra & $\% \mathrm{~m} / \mathrm{m} \mathrm{Al}_{2} \mathrm{O}_{3}$ disponível & $\% \mathrm{~m} / \mathrm{m} \mathrm{SiO}_{2}$ reativa \\
\hline $\mathrm{BC}$ & 47,2 & 5,3 \\
\hline $\mathrm{BCA}$ & 41,7 & 7,1 \\
\hline
\end{tabular}

\section{Estudo da Influência do pH na Distribuição Granulométrica}

Os ensaios foram realizados nas amostras de bauxita cristalizada (BC) e bauxita cristalizada amorfa (BCA) utilizando-se $1 \%$ e $4 \% \mathrm{~m} / \mathrm{m}$ do reagente alcalino em relação à polpa. Os resultados estão apresentados na Tabela 2.

Observa-se que a mudança no $\mathrm{pH}$ da polpa altera a distribuição granulométrica da bauxita. Nas amostras em que foi utilizado o reagente alcalino, houve um aumento percentual da fração com granulometria inferior a $37 \mu \mathrm{m}$, evidenciando que, de alguma forma, certas partículas antes não passantes pela peneira, conseguiram passar. Supõe-se que a mudança do $\mathrm{pH}$ do meio altere a carga superficial das partículas, de modo que, através de fenômenos de 
superfície complexos, as mesmas passam a apresentar repulsão e ocorre a quebra de agregados iônicos, ocasionando a formação de fragmentos de menor granulometria. Uma vez que, a caulinita apresenta granulometria inferior a $37 \mu \mathrm{m}$, é razoável se aceitar que o aumento da porcentagem passante seja devido ao aumento da quantidade deste mineral na fração fina. Outra hipótese é a de que ocorre a formação de algum composto intermediário, devido à reação entre o reagente alcalino utilizado e os minerais presentes na bauxita, que leva à formação de um sólido de granulometria fina, o que também elevaria a porcentagem passante pela peneira.

Tabela 2. Porcentagem mássica das frações obtidas via peneiramento a úmido das bauxitas submetidas ao estudo.

\begin{tabular}{|c|c|c|c|}
\hline Peneiramento a úmido & Secagem & Resu & ido Final \\
\hline Amostra & Massa Final (g) & $\begin{array}{l}\text { Massa Final Total } \\
\text { (g) }\end{array}$ & $\begin{array}{l}\text { Percentagem em } \\
\text { relação à massa final } \\
\text { total (\%) }\end{array}$ \\
\hline $\mathrm{BC}+37 \mu \mathrm{m}$ & 864,97 & \multirow{2}{*}{1002,28} & 86,30 \\
\hline $\mathrm{BC}-37 \mu \mathrm{m}$ & 137,11 & & 13,68 \\
\hline $\mathrm{BC} 1 \%+37 \mu \mathrm{m}$ & 720,28 & \multirow{2}{*}{1019,26} & 70,67 \\
\hline BC $1 \%-37 \mu m$ & 298,98 & & 29,33 \\
\hline $\mathrm{BC} 4 \%+37 \mu \mathrm{m}$ & 740,69 & \multirow{2}{*}{1098,12} & 67,45 \\
\hline $\mathrm{BC} 4 \%-37 \mu \mathrm{m}$ & 357,43 & & 32,55 \\
\hline $\mathrm{BCA}+37 \mu \mathrm{m}$ & 832,45 & \multirow{2}{*}{989,13} & 84,16 \\
\hline BCA - $37 \mu \mathrm{m}$ & 156,68 & & 15,84 \\
\hline BCA $1 \%+37 \mu \mathrm{m}$ & 696,74 & \multirow{2}{*}{1007,92} & 69,13 \\
\hline BCA $1 \%-37 \mu \mathrm{m}$ & 311,18 & & 30,87 \\
\hline BCA $4 \%+37 \mu \mathrm{m}$ & 698,19 & \multirow{2}{*}{1077,48} & 64,80 \\
\hline BCA 4\% - $37 \mu \mathrm{m}$ & 379,29 & & 35,20 \\
\hline $\begin{array}{l}1 \% \text { : Percentagem mássica de rea } \\
4 \text { \%: Percentagem mássica de rea } \\
+37 \mu \mathrm{m} \text { : Fração acima de } 37 \mu \mathrm{m} \\
\text { - } 37 \mu \mathrm{m} \text { : Fração abaixo de } 37 \mu \mathrm{m}\end{array}$ & $\begin{array}{l}\text { alcalino adicionado, } \\
\text { alcalino adicionado, }\end{array}$ & $\begin{array}{l}\text { relação à polpa. } \\
\text { relação à polpa. }\end{array}$ & \\
\hline
\end{tabular}

Ao compararmos os difratogramas das frações obtidas por meio de peneiramento, Figura 4, observa-se que as frações abaixo de $37 \mu \mathrm{m}$ apresentam picos intensos do mineral caulinita, indicando que tal mineral concentra-se nas frações mais finas. Observa-se também a formação da fase katoite, para o caso da BCA. 


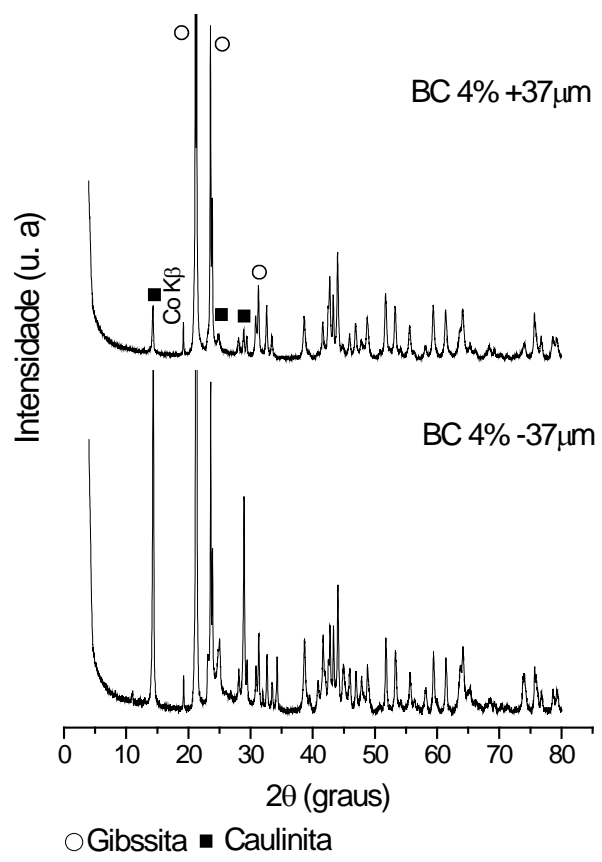

(A)

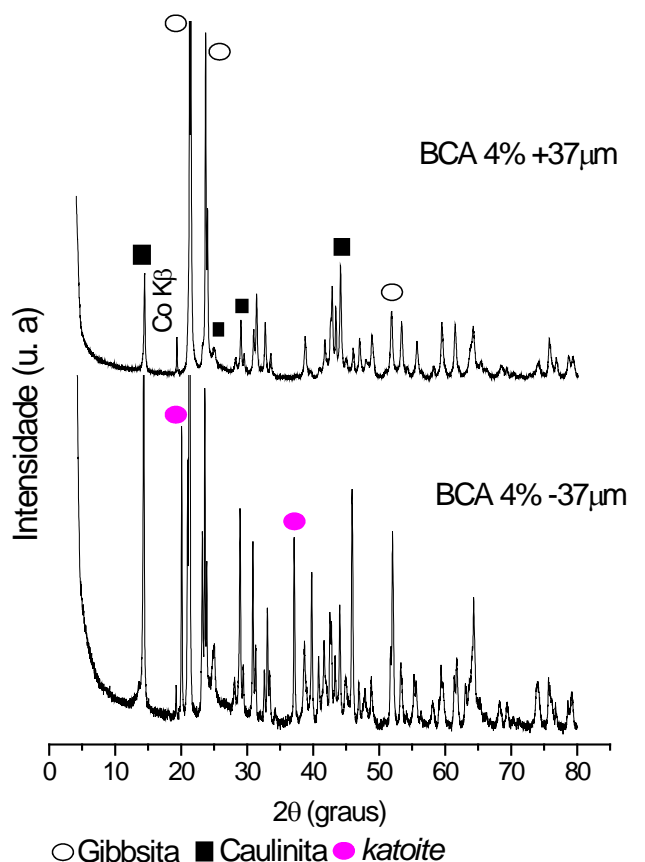

(B)

Figura 4. Difratogramas obtidos para as frações granulométricas das amostras de bauxita comercial e marginal submetidas ao estudo de $\mathrm{pH}$.

As análises de espectroscopia no infravermelho, das frações granulométricas obtidas após ensaio alcalino, Figura 5, permitiram observar que a fração abaixo de $37 \mu \mathrm{m}$ apresenta quatro bandas bem definidas em 3.696, 3.652, 1.035 e $914 \mathrm{~cm}^{-1}$, relativas ao mineral caulinita, que aparecem com baixa intensidade nas frações acima de $37 \mu \mathrm{m}$, o que corrobora com o comportamento observado nos difratogramas de raios $X$, confirmando que a caulinita concentra-se nas frações abaixo de $37 \mu \mathrm{m}$.

Conforme evidenciado pelos espectros, este aumento de intensidade ocorreu nas bandas verificadas em 3.696 e $3.652 \mathrm{~cm}^{-1}$, que são atribuídas ao modo de estiramento $\mathrm{OH}$ da caulinita, da banda em $1.035 \mathrm{~cm}^{-1}$, característica do estiramento das ligações Si-O da caulinita, e da banda em $914 \mathrm{~cm}^{-1}$, referente ao modo de deformação do grupo Al-O-H da caulinita, para as frações mais finas das duas bauxitas estudadas, Figura 5 (A) e (B).

As análises químicas realizadas para a bauxita comercial (BC) são apresentadas na Tabela 3. As análises da bauxita marginal (BCA) estão em etapa de desenvolvimento, uma vez que, o método de análise química utilizado mostrou-se muito trabalhoso e dispendioso, tanto em relação ao tempo de análise quanto ao uso de reagentes e preparo constante de soluções. Em função disto, tem-se buscado alternativas instrumentais para a determinação dos teores de alumina disponível e de sílica reativa, dentre as técnicas mais promissoras estão a análise térmica e a fluorescência de raios $X$. Vem-se tentando desenvolver as respectivas metodologias para análise, estando estas técnicas ainda em processo de estudo. 


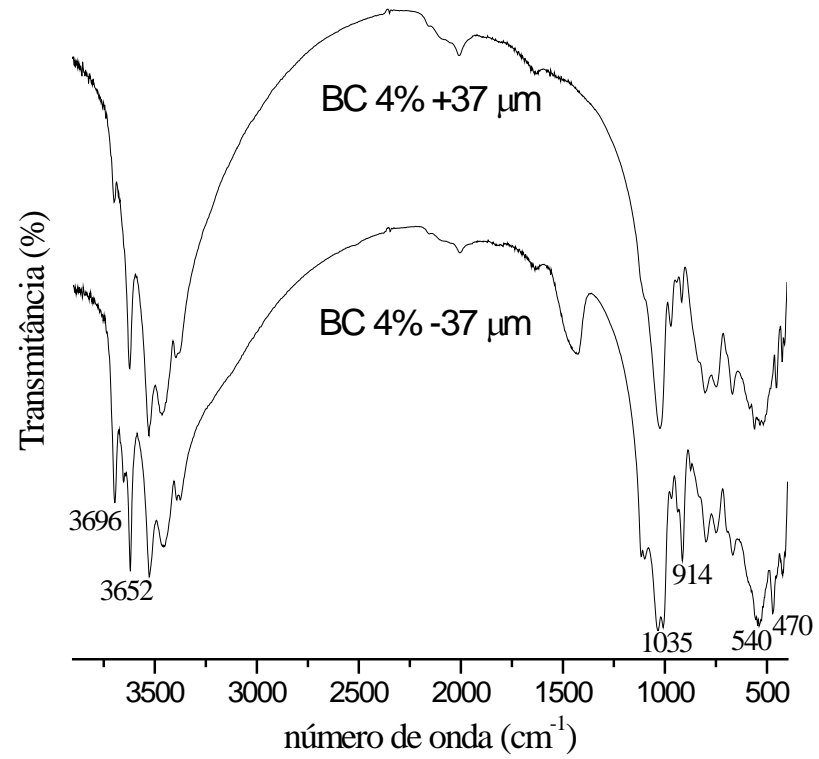

(A)

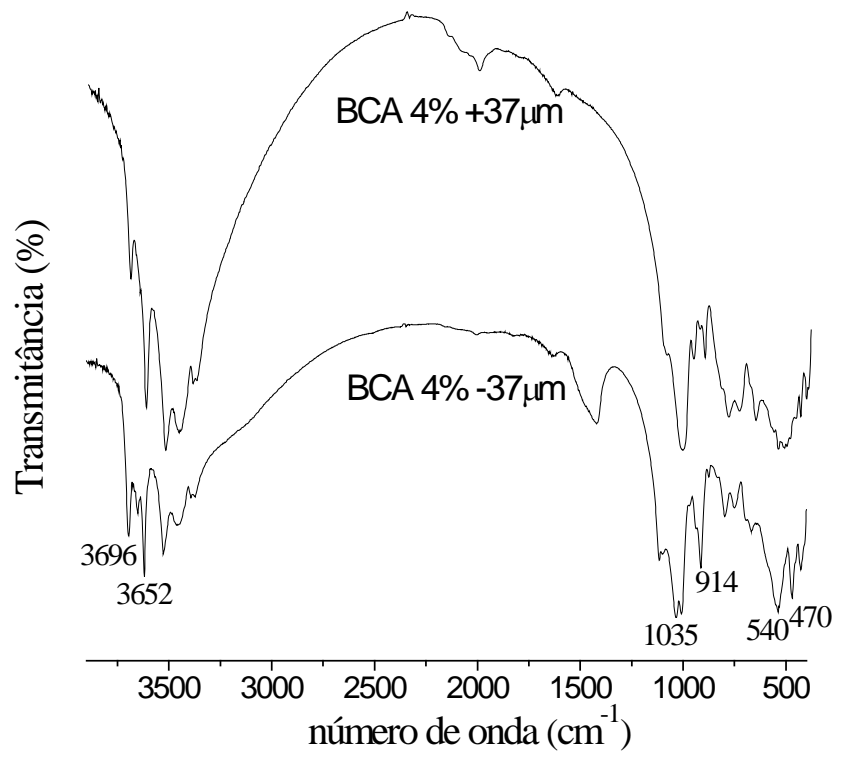

(B)

Figura 5. Espectros vibracionais na região do infravermelho para as frações da bauxita $B C \mathrm{e}$ BCA após ensaio alcalino.

Tabela 3. Resultados da análise química da bauxita comercial (BC), submetidas ao ensaio alcalino (1 e 4\%).

\begin{tabular}{|c|c|c|}
\hline Amostra & $\% \mathrm{~m} / \mathrm{m} \mathrm{Al}{ }_{2} \mathrm{O}_{3}$ disponível & $\% \mathrm{~m} / \mathrm{m} \mathrm{SiO} 2$ reativa \\
\hline $\mathrm{BC} 4 \%+37 \mu \mathrm{m}$ & 49,74 & 2,3 \\
\hline $\mathrm{BC} 4 \%-37 \mu \mathrm{m}$ & 22,91 & 16,5 \\
\hline \multicolumn{3}{|c|}{$\begin{array}{l}4 \text { \%: Percentagem mássica de reagente alcalino adicionado, em relação à polpa. } \\
+37 \mu \mathrm{m} \text { : Fração acima de } 37 \mu \mathrm{m} \\
-37 \mu \mathrm{m} \text { : Fração abaixo de } 37 \mu \mathrm{m}\end{array}$} \\
\hline
\end{tabular}

De acordo com os resultados exibidos na Tabela 3 observa-se, para o caso da bauxita $\mathrm{BC}$, o aumento do teor de $\mathrm{Al}_{2} \mathrm{O}_{3}$ disponivel e a redução do teor de $\mathrm{SiO}_{2}$ reativa nas frações mais grossas (acima de $37 \mu \mathrm{m}$ ), enquanto que na fração abaixo de $37 \mu \mathrm{m}$ um comportamento oposto foi observado. Sendo que, considerando-se os resultados obtidos para os dois tipos de bauxita estudados, por meio da distribuição granulométrica e pelas análises de DRX e de IV, em que é observada a diminuição do material retido nas frações mais grossas, assim como, o aumento na intensidade dos picos (DRX) e das bandas (IV), relacionadas à caulinita, nas frações mais finas, pode-se concluir que a adição do reagente alcalino contribui para a redução do teor de sílica reativa, nos dois tipos de bauxita estudados, caso a fração abaixo de $37 \mu \mathrm{m}$ seja removida.

\section{CONCLUSÕES}

De acordo com os resultados apresentados neste trabalho, conclui-se que: 
i) O controle do pH da polpa de bauxita altera sua distribuição granulométrica;

ii) Há indícios de que ocorre algum tipo de interação superficial entre as partículas minerais de gibsita e de caulinita presentes na bauxita;

iii) $\mathrm{O}$ controle do $\mathrm{pH}$ com um reagente alcalino parece ser uma alternativa promissora para a separação das partículas de caulinita e de gibbsita, via peneiramento a úmido.

\section{REFERÊNCIAS BIBLIOGRÁFICAS}

1. SILVA, F. A. N. G. Caracterização Estrutural e Estudo de Reatividade de Bauxita Contendo Sílica Reativa. Março 2011. 123 f. Tese (Doutorado em Ciências) - Instituto de Química, Universidade Federal do Rio de Janeiro, Rio de Janeiro. 2011.

2. GONÇALVES, Carlos H. A. Processos Eletrolíticos para Obtenção do Hidróxido de Sódio e do Alumínio. In: Carlos Henrique A. Gonçalves. (Org). Introdução aos Processos Químicos Industriais. 1a ed. Rio de Janeiro: 2008, p. 85-102.

3. SILVA, F. A. N. G.; SAMPAIO, J. A.; GARRIDO, F. M. S. ; MEDEIROS, Marta Eloisa. Study on the characterization of marginal bauxite from Pará/Brazil. Light Metals (New York), v. 2011, p. 13-18, 2011. doi: 10.1002/9781118061992.ch2

4. SILVA, F. A. N. G., BARBATO, C. N., SANTOS, R. D., ALMEIDA, D. S. G., SAMPAIO, J. A., MEDEIROS, M. E., GARRIDO, F. M. S. Mechanochemical Activation of Bauxite. Light Metals (New York), v. 2012, p. 27-32, 2012. doi: 10.1002/9781118359259.ch5

5. AQUINO, J. A.; OLIVEIRA, M. L. M. . Amostragem. In: João Alves Sampaio, Sílvia Cristina Alves França, Paulo Fernando Almeida Braga. (Org.). Práticas Laboratoriais em Tratamento de Minérios. 1 ed. Rio de Janeiro: CETEM, 2007, v. 1, p. 3-36.

6. BARBATO, C. N.; SAMPAIO, J. A. Ensaios de Moagem em Laboratório. In: João Alves Sampaio, Sílvia Cristina Alves França, Paulo Fernando Almeida Braga. (Org.). Práticas Laboratoriais em Tratamento de Minérios. 1 ed. Rio de Janeiro: CETEM, 2007, v. 1, p. 169178.

7. SILVA, F. A. N. G., MEDEIROS, M. E., SAMPAIO, J. A., SANTOS, R. D., CARNEIRO M. C., COSTA, L. S., GARRIDO, F. M. S. Technological Characterization of Bauxite from Pará-Brazil. Light Metals (New York), v. 2009, p. 139-144, 2009.

8. AZEVEDO, C. A.; GARRIDO, F. M. S.; MEDEIROS, M. E. The Effect of Mechanochemical Activation in the $\mathrm{MgO}-\mathrm{Al}_{2} \mathrm{O}_{3}-\mathrm{SiO}_{2}$ System Reactivite. Journal of Thermal Analysis and Calorimetry, v. 83, p. 649-655, 2006.

9. SILVA, F. A. N. G.; GARRIDO, F. M. S.; MEDEIROS, Marta Eloisa; SAMPAIO, J. A.. Processo de Redução do Teor de Sílica Reativa Contida em Bauxita para Posterior Utilização 
no Processo Bayer. Pedido de patente №: BR 1020120046296 A2, INPI, Rio de Janeiro, 2012.

10. SILVA, F. A. N. G.; SAMPAIO, J. A. Análise Granulométrica Por Peneiramento. In: João Alves Sampaio, Sílvia Cristina Alves França, Paulo Fernando Almeida Braga. (Org.). Práticas Laboratoriais em Tratamento de Minérios. 1 ed. Rio de Janeiro: CETEM, 2007, v. 1, p. 55-74.

11. SILVA, F. A. N. G.; MEDEIROS, M. E; SAMPAIO, J. A.; SANTOS, R. D.; GARRIDO, F. M. S.. Study on Ore Dressing and Characterization of Different Granulometric Fractions that Compound Bauxite from Pará/Brazil. Light Metals (New York), v. 2010, p. 69-74, 2010. 